University for Business and Technology in Kosovo

UBT Knowledge Center

UBT International Conference

2015 UBT International Conference

Nov 7th, 9:00 AM - 5:00 PM

\title{
Design of bearing capacity of the driven piles of a highway bridge foundation according to 3 different methods
}

\author{
Papa Dhimitri \\ Polytechnic University of Tirana, dhimitri.papa@gmail.com \\ Dervishi Idlir \\ Polytechnic University of Tirana, idlirdervishi@hotmail.com
}

Follow this and additional works at: https://knowledgecenter.ubt-uni.net/conference

Part of the Civil Engineering Commons, and the Structural Engineering Commons

\section{Recommended Citation \\ Dhimitri, Papa and Idlir, Dervishi, "Design of bearing capacity of the driven piles of a highway bridge foundation according to 3 different methods" (2015). UBT International Conference. 76. \\ https://knowledgecenter.ubt-uni.net/conference/2015/all-events/76}

This Event is brought to you for free and open access by the Publication and Journals at UBT Knowledge Center. It has been accepted for inclusion in UBT International Conference by an authorized administrator of UBT Knowledge Center. For more information, please contact knowledge.center@ubt-uni.net. 


\title{
Design of bearing capacity of the driven piles of a highway bridge foundation according to 3 different methods
}

\author{
Papa Dhimitri1 ${ }^{1}$, Dervishi Idlir ${ }^{2}$ \\ ${ }^{1,2}$ Faculty of Civil Engineering, Polytechnic University of Tirana, Albania \\ dhimitri.papa@gmail.com ${ }^{1}$, idlirdervishi@hotmail.co $\mathrm{m}^{2}$
}

\begin{abstract}
Contemporary design methods of bearing capacity of deep foundation (pile foundation) change according to different design codes. The main requisition of the designing process of the deep foundation is related with the axial bearing capacity, which should be sufficient to withstand the applied loads. Many authors has developed and published detailed methods to analyze the behavior of a single reinforced concrete pile or a group of piles, based on vertical bearing capacity due to lateral friction or residence at the pile point. The goal of this paper is to illustrate the calculation methods according to 3 analytical methods of vertical bearing capacity of bored single pile and group of piles of a bridge foundation. Only the vertical loads are considered during the design process. Shear loads and bending moment act as horizontal loads on the group of piles. A comparison between three different methods is shown to determine the bearing capacity and the stress limit allowed. The bridge is located in the 26 kilometer of Elbasan-Tiranë highway.
\end{abstract}

Keywords: Bearing capacity, reinforce concrete pile, lateral friction, bored piles.

\section{Introduction}

The bridge is located in the 26 kilometer of Elbasan-Tiranë highway. In this paper a comparison between three different methods is shown to determine the bearing capacity and the stress limit allowed. Determination of the bearing capacity of a bored pile is studied in details by many different researchers. Given that in the deep foundations reinforced concrete piles are usually placed in a group, it is very important to determine the bearing capacity of the group of piles. Bringing the group of piles is more complex, but less studied as a whole. In this paper, the deep foundation is represented by a group of 15 piles of reinforced concrete cast in place. The piles have lengths of $12.0 \mathrm{~m}$ (D) and are placed in two different geological layers (Figure 1), referred to the report of the Geological Survey. It is calculated the allowed bearing capacity during the fixing process of a bored pile by three different analy tical methods:

According to the methodology of CODUTO [1] [2]:

$$
P_{a}=\frac{\mathrm{q}_{\mathrm{t}}^{\prime} A_{t}+\sum f_{s} A_{s}}{\mathrm{~F}}
$$

According to Albania Design Practice [3]:

$$
P_{d}=m k_{d w} \times\left(m_{\sigma} q_{t}^{\prime} A_{t}+m_{f} \Sigma f_{s} A_{s}\right)
$$

According to Japanese Design Practice [3]:

$$
P_{a}=\frac{1}{3}\left(q_{t}^{\prime} A_{t}+P_{s}\right)=\frac{1}{3}\left(q_{t}^{\prime} A_{t}+\left(\frac{10}{3} \overline{N_{s}} L_{s}+\frac{1}{2} \overline{q_{u}} L_{c}\right) \varphi\right)
$$


After establishing the allowed bearing capacity and the boundary for a bored pile for each of the above methodologies, it is also determined the effect of the group of piles based on the method of CODUTO through the effectiveness of the group coefficient $\eta$. The results obtained by each method are compared analytically and graphically. A detailed study of geological-engineering [4], performed by the Geotechnical Studio "GEO-Terra" and based on two geological drillings (BH-I and BH-II), amounting to $25.0 \mathrm{~m}$ of depth, is performed in advance in order to determine the geotechnical parameters of the layers, where the foundation will be fixed. The geometry of the foundation piles beam is given in (Figure 2). The distance between the piles in the group is taken in order of 2.5-3 from the diameter of the pile. The diameter of the piles is obtained $\mathrm{B}=1.20 \mathrm{~m}=120 \mathrm{~cm}$ and length of $\mathrm{D}=12.0 \mathrm{~m}$.

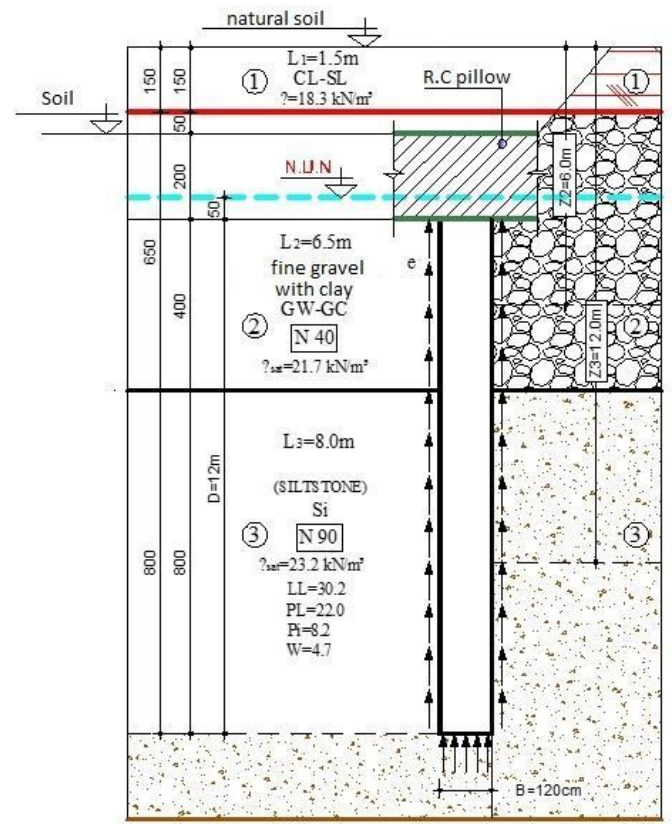

Figure 1: Geological Profile and Setting of the Pile

The piles group is designed with low height pads of $\mathrm{H}=2.0 \mathrm{~m}$. By taking in consideration the loads of microstructure, where are included the permanent ones, temporary ones and the weight of soil, there is also defined the foundation design load that operates in the group of piles. Vertical loads, because of the over-structure of the bridge and the weight

of the foundation itself, is $\mathrm{Pu}=45^{\prime} 640 \mathrm{kN}$, horizontal loads caused by lateral earth/soil pressure is $\mathrm{Vu}$ $=9^{\prime} 975 \mathrm{kN}$ and the maximum $/$ climax moment is $\mathrm{Mu}=26^{\prime} 400 \mathrm{kNm}$.

\section{Calculation of axial bearing capacity during pile fixing process}

\subsection{Calculation of bearing capacity by CODUTO}

In terms of the resistance at the pile point and in lateral friction, the allowed bearing capacity during the fixing process of the bored pile is determined by the equation:

$$
P_{a}=\frac{\mathrm{q}_{\mathrm{t}}^{\prime} A_{t}+\sum f_{s} A_{s}}{\mathrm{~F}}
$$

Are determined the coefficients and terms that participate in the above equation: 


\section{$F=3$ Safety factors}

Bearing surface of contact at the pile point:

$$
A_{t}=\frac{\pi B^{2}}{4}=\frac{3.1415 \times 1.2^{2}}{4}=1.13 \mathrm{~m}^{2}
$$

Net bearing resistance at the pile point defined by the formula:

$$
q^{\prime}{ }_{t}=57.5 \times N_{60}
$$

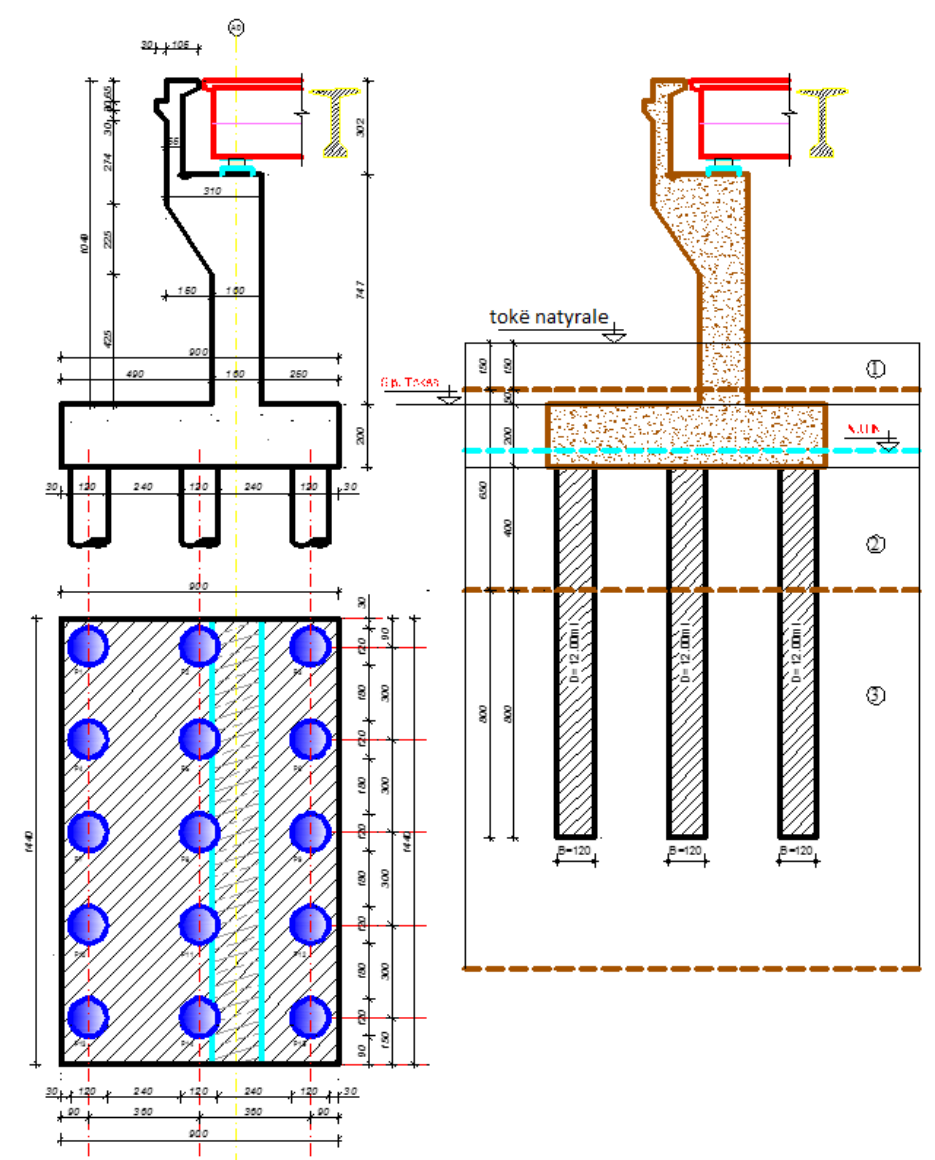

Figure 2: The Group of Foundation Piles of the Bridge in the Highway

$$
N_{60}=\frac{\mathrm{E}_{\mathrm{m}} \times \mathrm{C}_{\mathrm{B}} \times \mathrm{C}_{\mathrm{S}} \times \mathrm{C}_{\mathrm{R}} \times \mathrm{N}}{0.60}
$$

$E_{m}=0.45$ from the table $4.3 \mathrm{pg} .119$ [1] 
$C_{B}=1.05$ from the table $4.4 \mathrm{pg} .120[1]$

$C_{s}=1.00$ from the table $4.4 \mathrm{pg} .120[1]$

$C_{R}=0.85$ from the table 4.4 pg.120 [1]

$N=90$ the value is measured by SPT laboratory tests

By replacing the above values in equation (3) is found the value for $N_{60}$ :

$$
N_{60}=\frac{0.45 \times 1.05 \times 1 \times 0.85 \times 90}{0.60}=60.24
$$

Also, is defined the effective vertical stress $\sigma_{Z}^{\prime}$ at the pile point as follows:

$$
\begin{aligned}
\sigma_{Z}^{\prime} & =\gamma_{1} L_{1}+\gamma_{2} L_{2}+\left(\gamma_{2, \text { sat }}-\gamma_{w}\right) L_{2, \text { sat }}+\left(\gamma_{3, \text { sat }}-\gamma_{w}\right) L_{3}= \\
& =18.3 \times 1.5+19.7 \times 2.0+(21.7-9.81) \times 4.5+(23.2-9.81) \times 8=230 \mathrm{kPa}
\end{aligned}
$$

As $\sigma_{Z}^{\prime}=230 \mathrm{kPa}>100 \mathrm{kPa}$ defines $\left(N_{1}\right)_{60}$, the adjusted value for $N_{60}$ is defined by the following equation:

$$
\left(N_{1}\right)_{60}=N_{60} \sqrt{\frac{100 \mathrm{kPa}}{\sigma_{z}^{\prime}}}=60.24 \times \sqrt{\frac{100}{230}}=39.75
$$

By replacing we determine the value of $\mathrm{q}_{\mathrm{t}}^{\prime}$ :

$$
\mathrm{q}_{\mathrm{t}}^{\prime}=57.5 \times\left(N_{1}\right)_{60}=57.5 \times 39.75=2285.5 \mathrm{kPa}
$$

It is determined the lateral surface of the contact of the pile with layer 2 and 3 :

$$
\begin{aligned}
& A_{s 2}=\pi \mathrm{BL}_{2}=3.14 \times 1.2 \times 4.0=15.07 \mathrm{~m}^{2} \\
& A_{s 3}=\pi \mathrm{BL}_{3}=3.14 \times 1.2 \times 8.0=30.14 \mathrm{~m}^{2}
\end{aligned}
$$

It is calculated the value of unit resistance in lateral friction according to Method $\beta$ [1] for the second layer:

$$
f_{s 2}=\beta \times \sigma_{z 2}^{\prime}=1.15 \times 96.5=112.2 \mathrm{kPa}
$$


Where:

$$
\beta=1.5-0.245 \sqrt{z}=1.5-0.245 \sqrt{2.0}=1.15
$$

$\mathrm{z}=2.00 \mathrm{~m}$ it is the depth of the middle of the second geological layer

Value of $\beta$ is accepted in accordance with the above results, after:

$$
\left(N_{1}\right)_{60}=39.75>15
$$

$\sigma_{Z 2}^{\prime}$ Effective vertical stress among the second layer, which is defined as:

$$
\begin{aligned}
\sigma_{Z 2}^{\prime} & =\gamma_{1} L_{1}+\gamma_{2} L_{2}+\left(\gamma_{2, \text { sat }}-\gamma_{w}\right)\left(z_{2}-L_{1}-L_{2}\right)= \\
& =18.3 \times 1.5+19.7 \times 2.0+(21.7-9.81)(6-1.5-2)=96.57 \mathrm{kPa}
\end{aligned}
$$

It is calculated the value of unit resistance in lateral friction according to Method $\beta$ [1] for the third layer:

$$
f_{s 3}=\beta \times \sigma_{Z 3}^{\prime}=0.8 \times 174.2=139.2 \mathrm{kPa}
$$

Where:

$$
\begin{aligned}
& \beta=1.5-0.245 \sqrt{\mathrm{z}}=1.5-0.245 \sqrt{8.0}=0.80 \\
& \mathrm{z}=8.00 \mathrm{~m} \text { it is the depth of the middle of the third geological layer }
\end{aligned}
$$

Value of $\beta$ is accepted in accordance with the above results, after

$$
\left(N_{1}\right)_{60}=39.75>15
$$

$\sigma_{Z 3}^{\prime}$ effective vertical stress among the second layer, which is defined as:

$$
\begin{aligned}
\sigma_{Z 3}^{\prime} & =\gamma_{1} L_{1}+\gamma_{2} L_{2}+\left(\gamma_{2, \text { sat }}-\gamma_{w}\right) L_{2, \text { sat }}+\left(\gamma_{3, \text { sat }}-\gamma_{w}\right) \frac{\mathrm{L}_{3}}{2}= \\
& =18.3 \times 1.5+19.7 \times 2.0+(21.7-9.81) \times 4.5+(23.2-9.81) \frac{8}{2}= \\
& =174.2 \mathrm{kPa}
\end{aligned}
$$

Allowed bearing capacity during the fixing process of the bored pile, according to the methodology [1] results in:

$$
\begin{aligned}
P_{a}=\frac{\mathrm{q}_{\mathrm{t}}^{\prime} A_{t}+\sum f_{s} A_{s}}{\mathrm{~F}} & =\frac{2285.5 \times 1.13+(112.2 \times 15.07)+(139.2 \times 30.14)}{3} \\
& =2823.1 \mathrm{kN}
\end{aligned}
$$


Boundary bearing capacity during pile fixing process will be:

$$
P_{\text {ult }}=P_{a} F=2823.1 \times 3=8469.3 k N
$$

Allowed bearing capacity during the fixing process of the bored pile, according to the methodology [1] results in:

$$
P_{a g}=\eta \times N \times P_{a}
$$

By using the efficiency factor of the group, it results in:

$$
\eta=1-\theta \frac{(n-1) m+(m-1) n}{90 \times m \times n}
$$

Where:

$m=5$ number of rows of piles

$n=3$ number of piles in a row

$\theta=\operatorname{tg}^{-1}\left(\frac{B}{s}\right)=\operatorname{tg}^{-1}\left(\frac{1.2}{3.6}\right)=15.48$

$S=3.6 \mathrm{~m}$ is the axial distance between piles

$B=1.2 \mathrm{~m}$ is the diameter of pile

$$
\eta=1-15.48 \frac{(3-1) \times 5+(5-1) \times 3}{90 \times 5 \times 3}=1-15.48 \times 0.0162=0.75
$$

is defined the allowed and boundary bearing capacity in the group of piles ( $\mathrm{N}=15$ piles):

$$
\begin{gathered}
P_{a g}=0.75 \times 15 \times 2823=31760 k N \\
P_{a g, u l t}=0.75 \times 15 \times 8469=95276 k N
\end{gathered}
$$

\subsection{The calculation of the bearing capacity by Albania Design Practice}

Bearing capacity during the fixing process (compression) $P d$ of the design of a pile, taking into account the resistance in lateral friction at the pile point and the resistance is calculated by the following formula [2]:

$$
P d=m k d w \times\left(m \sigma q t^{\prime} A t+m f \Sigma f s A s\right)
$$

Where:

$m=0.65 \rightarrow$ Coefficient of working conditions for piles cast in place

$k d w=0.7 \rightarrow \quad$ In case of bearing capacity of piles which are working during the fixing process

$m \sigma=0.9 \rightarrow$ Coefficient of working conditions at the pile point

$m f=0.6 \rightarrow$ Coefficient of working conditions on the lateral part of the pile

It is determined the contact surface at the pile point $A t$ : 


$$
A_{t}=\frac{\pi \mathrm{B}^{2}}{4}=\frac{3.1415 \times 1.2^{2}}{4}=1.13 \mathrm{~m}^{2}
$$

It is determined the lateral contact surface during rubbing $A_{s}$ for the geological layers 2 and 3:

$$
\begin{aligned}
& A_{s 2}=\pi \mathrm{BL}_{2}=3.14 \times 1.2 \times 4=15.07 \mathrm{~m}^{2} \quad \text { (layer 2) } \\
& A_{s 3}=\pi \mathrm{BL}_{2}=3.14 \times 1.2 \times 8=30.14 \mathrm{~m}^{2} \quad \text { (layer 3) }
\end{aligned}
$$

It is determined unit resistance in lateral rubbing $f_{s}$ for the geological layers 2 and 3 :

$$
\begin{aligned}
& f_{s 2}=53 \mathrm{kPa} \text {, (layer 2) for } z_{2}=4 \mathrm{~m} \text { and } I=0.3 \\
& f_{s 3}=65 \mathrm{kPa} \text {, (layer 3) for } z=10 \mathrm{~m} \text { and } I=0.2
\end{aligned}
$$

It is determined the net resistance at the pile point $q_{t}^{\prime}$ :

$$
q_{t}^{\prime}=10860 \mathrm{kPa}
$$

By replacing values, we would have the value of axial bearing capacity:

$$
\begin{gathered}
P_{d}=m k_{d w} \times\left(m_{\sigma} q_{t}^{\prime} A_{t}+m_{f} \Sigma f_{s} A_{s}\right)= \\
=0.65 \times 0.7 \times[0.9 \times 10860 \times 1.13+0.6 \times(53 \times 15.07+65 \times 30.14)]= \\
=5778.0 \mathrm{kN}
\end{gathered}
$$

Considering that the Albanian Design Practice recommends a safety factor equal to 1.68 , boundary bearing capacity during the fixing process of the pile will be:

$$
P_{u l t}=P_{d} \times \mathrm{F}=5778 \times 1.68=9707 \mathrm{kN}
$$

\subsection{Calculation of bearing capacity by Japanese Design Practice}

According to Japanese Standards for buildings, allowed bearing capacity in the fixing process $P a$ of the pile foundation is determined by the following formula, based on the dates of SPT test:

$$
P a=\frac{1}{3}\left(q_{t}^{\prime} A t+P s\right)
$$


Where:

$$
q_{t}^{\prime}=150 \bar{N}=150 \times 60=9000 \mathrm{kPa} \text { for piles of concrete cast in place }
$$

Bearing surface of contact at the pile point $A_{t}$ :

$$
A_{t}=\frac{\pi \mathrm{B}^{2}}{4}=\frac{3.1415 \times 1.2^{2}}{4}=1.13 \mathrm{~m}^{2}
$$

Resistance during lateral rubbing is determined by the following formula:

$$
P_{s}=\left(\frac{10}{3} \overline{N_{s}} L_{s}+\frac{1}{2} \overline{q_{u}} L_{c}\right) \varphi
$$

Where:

$$
\begin{aligned}
\varphi & =2 \pi \mathrm{r}=3.768 \mathrm{~m} \\
\overline{N_{s}} & =30 \\
\mathrm{~L}_{s} & =12.00 \mathrm{ml} \\
\overline{q_{u}} & =0 \mathrm{kPa} \text { Average compressive resistance to axial clay soil } \\
L_{c} & =0 \mathrm{~m} \text { Total length of pile in contact with clay soils }
\end{aligned}
$$

$$
P_{s}=\left(\frac{10}{3} \times 30 \times 12\right) 3.768=4521.6 \mathrm{kN}
$$

By making the replacements in the equation 4, we will obtain the value of axial bearing capacity:

$$
P_{a}=\frac{1}{3} \times(9000 \times 1.13+4521.6)=4897.2 \mathrm{kN}
$$

Japan's Building Standard recommends a safety factor equal to 3 , so that boundary bearing capacity will be:

$$
P_{u l t}=P_{a} \times \mathrm{F}=4897.2 \mathrm{kN} \times 3=14691.6 \mathrm{kN}
$$

\section{Conclusions}

1. The group of the foundation piles of the bridge in the highway is represented by 15 piles with diameter of $1.20 \mathrm{~m}$ and length of $12.00 \mathrm{ml}$.

2. The method of calculation according to CODUTO foresees the calculation of bearing capacity of the group of piles in vertical load, based on the bearing capacity of the bored pile, coefficient of efficiency of the group and the number of piles. In Albanian and Japanese practices design, this calculation is not provided.

3. The allowed values of the bearing capacity of the bored pile with vertical load calculated according to the methods mentioned above have resulted in:

According to Coduto: $P_{\mathrm{a}}=2823.1 \mathrm{kN}$

According to Albanian Practice: $P_{\mathrm{d}}=5778.0 \mathrm{kN}$

According to Japonese Practice: $P_{\mathrm{a}}=4897.2 \mathrm{kN}$

Graphically, the values stated above are presented in the chart below (Figure 3): 


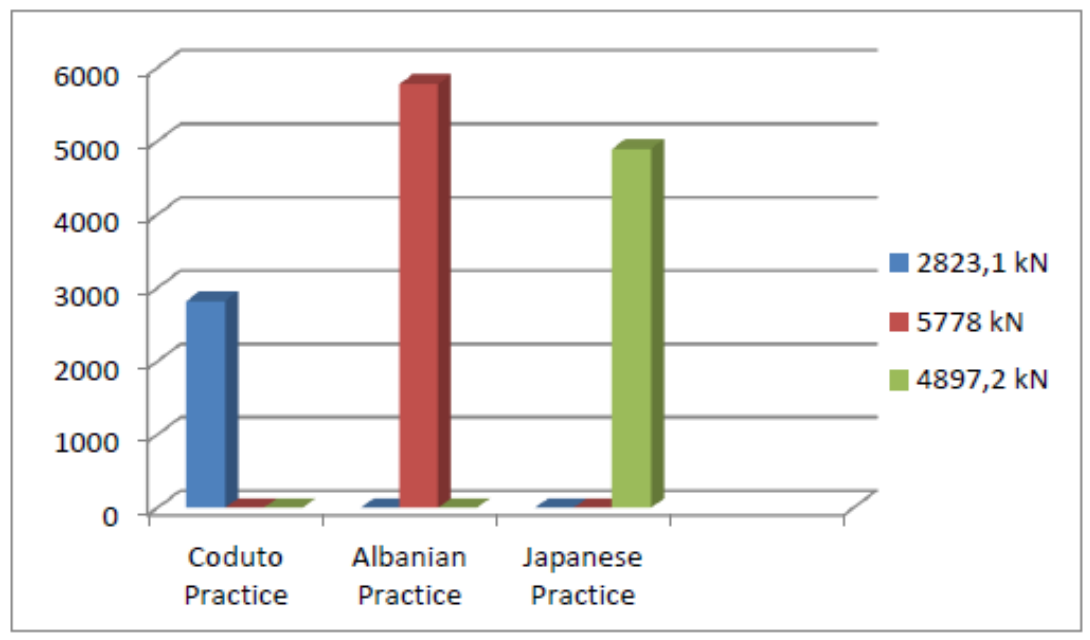

Figure 3. Comparison of Allowed Bearing Capacity [kN]

4. The values of bearing capacity of bored border pile on vertical lord calculated according to the methods mentioned above have resulted in:

According to Coduto: Pult $=8469.3 \mathrm{kN}$

According to Albanian Practice: $P u l t=9707.0 \mathrm{kN}$

According to Japanese Practice: Pult $=14691.6 \mathrm{kN}$

Graphically, the values stated above are presented in the chart below (Fig.4):

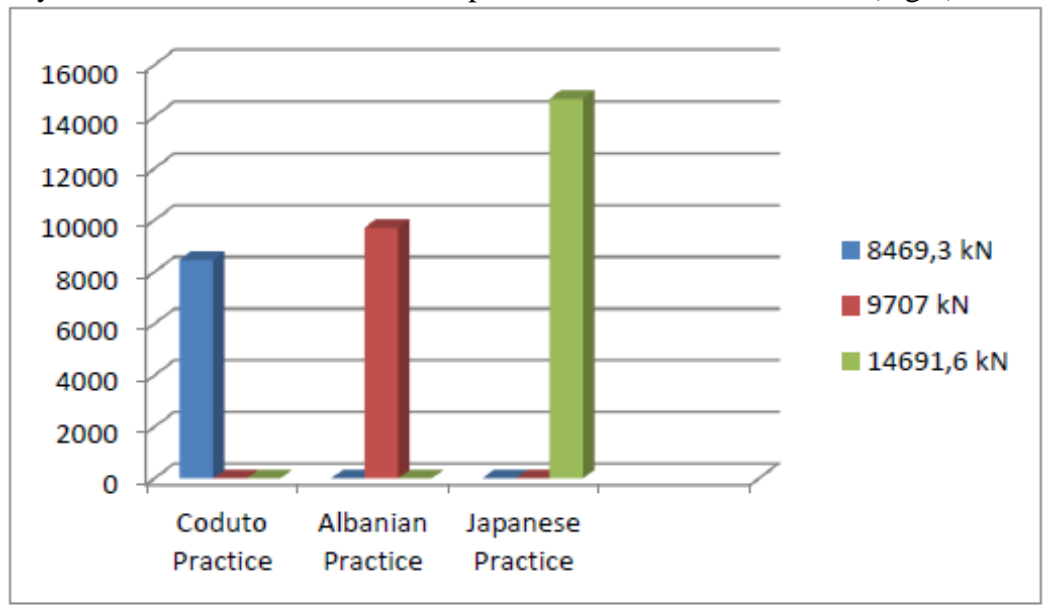

Figure 4. Comparison of the Boarder Bearing Capacity $[\mathrm{kN}]$

5. Allowed bearing capacity of the bored pile calculated by Albanian practice results in $90 \%$ higher than that calculated under Coduto, and $18 \%$ higher than that calculated under Japanese practice.

6. Border bearing capacity of bored pile calculated by Albanian practice results in $14.6 \%$ higher than that calculated under Coduto, but $50 \%$ lower than that calculated by the Japanese Practice.

7. For the group of piles we are studying, the effectiveness factor of the group resulted $\eta=0.75$. Allowed capacity for the group has resulted $\mathrm{Pag}=31759.8 \mathrm{kN}$ and the border one Pag,ult=95 276 $\mathrm{kN}$. The design load that acts on the foundation is $\mathrm{Pu}=45650 \mathrm{kN}$. 


\section{References}

1. FOUNDATION DESIGN, Principles and Practices, DONALD P. CODUTO, Second Edition, Prentice Hall Inc., (2001)

2. THEMELET E THELLA, Ushtrime të Zgjidhura, Dr. Eng. Neritan SHKODRANI, UPT-FIN, Tiranë (2001)

3. DINAMIKA E PILOTAVE, Parimet Bazë dhe Zbatime, NERITAN J. SHKODRANI, UPTFIN, Tiranë (2001)

4. GEOTECHNICALEVALUATION \& FOUNDATION DESIGN OF BRIDGE, FROM CH $25 .+734$ to $\mathrm{CH}$. 25.+805, GEO Terra \& CO, Athens 2012

5. PRINCIPLES OF FOUNDATIONENGINEERING, Braja M. Das, 4th EDITION 